\title{
Comparison of field methods for measuring surface topography and their associations with a tropical reef fish assemblage
}

\author{
Mark I. McCormick \\ Department of Marine Biology, James Cook University, Townsville, Queensland 4811, Australia
}

\begin{abstract}
The relationships between 6 measures of substratum topography or vertical relief and a tropical fish assemblage were evaluated and the merits of the various measures were assessed. A method of quantifying surface topography in the field using a profile gauge is introduced and found to be rapid and to generate concise summary statistics. Of the 6 measures of substratum topography compared, 1 was novel, 2 were derivations of geomorphological techniques and 3 had been previously used in reef fish studies. Measures included the sum of consecutive substratum height differences, vector standard deviation (SD), substratum angle SD, substratum height SD, substratum height coefficient of variation (CV) and the ratio of contoured surface distance to linear distance ('chain-and-tape'). All but the $\mathrm{CV}$ were found to grossly differentiate among surfaces that varied in corrugation height and frequency. Consecutive substratum height difference, substratum angle SD and vector SD were best able to differentiate between 9 schematic profiles of varying topography. A field test of the methods was carried out on 100 quadrats $(3 \times 3 \mathrm{~m})$ from the backreef of Lizard Island, northern Great Barrier Reef, Australia, in which the surface topography, fish and benthic communities had been sampled. The consecutive height difference method performed consistently well, scoring the highest average correlations with total fish abundance, diversity and the abundance of individual species. In an examination of the relationship between the backreef fish assemblage, substratum topography and the cover of benthic organisms, topography was only secondary in importance to depth in describing the patterns of damselfish abundance at the scale sampled.
\end{abstract}

KEY WORDS: Surface topography $\cdot$ Habitat complexity $\cdot$ Reef fish $\cdot$ Methodology

\section{INTRODUCTION}

Habitat complexity, or the spatial arrangement and diversity of surface types, is an important factor governing the abundance patterns of many marine organisms. Marked settlement preferences related to surface complexity have been recorded for invertebrate groups such as barnacles (Crisp \& Barnes 1954), sponges (Russ 1980) and scleractinian corals (Carleton \& Sammarco 1987). Similarly, many demersal fish show marked settlement preferences for substrata with specific structural features (e.g. Marliave 1977, Sale et al. 1984, Eckert 1985, Levin 1991, Green 1994). Surface complexity may influence the movement patterns of organisms (Raffaelli \& Hughes 1978, Reese 1989) and is often concomitant with availability of food and shel- ter (Hacker \& Steneck 1990). It may also modify the processes of recruitment, competition and predation (Jones 1988a, Hixon \& Beets 1993). The breadth of interactions among the physical and biotic components that define habitat complexity, and the scale dependence of these interactions, have resulted in a diversity of definitions and ways of measuring habitat complexity (McCoy \& Bell 1991, Sebens 1991).

In tropical systems, few studies have addressed the relationship between habitat complexity and reef fish assemblages. Those that have examined them found conflicting results. Carpenter et al. (1981) demonstrated a strong correlation between fish biomass, but not total abundance, and substratum complexity. Luckhurst \& Luckhurst (1978) found fish abundance and substratum complexity were strongly correlated at 
only 1 of the 2 sites studied. Roberts \& Ormond (1987) noted that none of the 3 measures of structural complexity used were significantly correlated with species richness or abundance of small, strongly site-attached fish. This conflict may be due partly to the diverse habits of the fish examined. Use of summary statistics, such as total abundance or species richness, may mask trends at the individual species level when pooled across species, trophic groups or guilds. Strongly siteattached fish, or those with obligate associations, tend to have higher correlations with certain aspects of the substratum than more widely ranging species or life stages.

This conflict of results may also be due to the diverse ways of measuring substratum complexity. The majority of studies have used the percentage cover of coral taxa and life-form categories as a measure of habitat complexity (e.g. McManus et al. 1981, Bell \& Galzin 1984, Bouchon-Navaro \& Bouchon 1989, Levin 1991). In a few instances surface attributes such as hole size, slope and height have been combined with percentage cover (Sale et al. 1984, Roberts \& Ormond 1987, Levin 1991). Luckhurst \& Luckhurst (1978) used the ratio of the length of a chain contoured over the surface to the linear distance between the chain's end-points as a measure of surface complexity. The current study presents a preliminary investigation of a range of methods of quantifying surface complexity and assesses their usefulness in descriptions of reef fish distributions.

Habitat complexity envelops both the diversity of vertical relief (the terms topography, rugosity or architecture have been used synonymously) and diversity of substratum types (species or life forms). Percentage cover adequately describes the cover of sessile fauna, and many reviews of sampling techniques exist. In contrast, despite the need for concise and unambiguous ways of quantifying surface topography in descriptions of fish ecology, few methods have been used and there is currently no assessment of the suitability of techniques. Surface topography has 2 components: (1) frequency and amplitude of corrugation, and (2) degree of angulation (i.e. frequency distribution of slopes of the substratum; Hobson 1972). Together these give an overall summary of the 3-dimensionality of the surface. Hobson (1972), in a discussion of spatial analysis in geomorphology, noted that for a measure of surface complexity to be useful it must have 3 characteristics: conceptually descriptive, easily measured in the field, and capable of being measured and compared on a number of spatial scales.

The present study introduces a method of collecting data on surface topography, not previously used by fish ecologists, that is rapid and can be used to generate concise summary statistics. It introduces a new summary statistic and evaluates its merits along with 5 other ways of quantifying surface topography; 3 of which are currently used, and 2 of which are derived from geomorphological techniques. The ability of these 6 statistics to differentiate among a range of surface profiles is assessed by simulation and their relationship to fish total abundance and diversity is examined using field data. Lastly, the complex relationship between fish distribution patterns, surface relief and the benthic community is stressed by examination of the relationships in $3 \times 3 \mathrm{~m}$ field quadrats from a tropical reef.

\section{MATERIALS AND METHODS}

Study site and sampling. The study was conducted on the backreef of Lizard Island (14 $\left.44^{\prime} \mathrm{S}, 145^{\circ} 28^{\prime} \mathrm{E}\right)$ on the northern Great Barrier Reef, Australia, during December 1989. Sampling units were randomly allocated to a 1.75 ha area of reef, from a cliff base $(1 \mathrm{~m}$ below MLW) to the reef edge (13 to $15 \mathrm{~m}$ ). The randomisation procedure was as follows: at approximately the middle of the study area a quadrat was dropped over the side of the dive tender, from this initial point 2 random numbers ( 1 to 50 ) determined the position of the sampling unit along two $50 \mathrm{~m}$ tapes; the first tape determined the longshore distance (1 to 25 upshore, 26 to 50 downshore), the second tape the distance offshore ( 1 to 25 shoreward, 26 to 50 seaward). One hundred $3 \times 3 \mathrm{~m}$ quadrats were sampled for fish assemblage composition, cover of benthic organisms and reef topography. Quadrat perimeters were delimited by a fibreglass tape measure. This scale of sampling was chosen to coincide with the approximate territory size of many small reef fish (e.g. Fig. 2 from Sale 1978, Roberts 1987).

Once the tape had been laid, the quadrats were left for 10 to $15 \mathrm{~min}$ prior to censusing fishes to reduce biases due to disturbance. After this recovery period fishes appeared to have returned to their pre-existing distribution patterns. When the quadrat was approached for census the large fish species that showed diver avoidance or attraction were recorded first (e.g. adult scarids, siganids, lutjanids, large labrids), followed by those species that did not respond to diver presence. Fishes were identified to species level and recorded as recently recruited individuals (by pigmentation patterns or body size) or adults. Ninety-five species were recorded. Small cryptic fishes, such as many of the blenniids, gobiids and serranids, were not recorded due to the low probability of achieving an accurate census.

To estimate the percentage cover of benthic organisms three $1 \times 1 \mathrm{~m}$ non-overlapping girded quadrats (121 intercepts) were placed in each $3 \times 3 \mathrm{~m}$ quadrat to 
obtain a representative sample of the benthic community. Benthic substrata under the intercepts were placed into one of 17 categories, chosen to include all the major benthic growth forms: 10 hard coral groups (Stylophora pistillata; Pocillopora sp., Montipora sp., Acropora bushy, Acropora plate, Acropora branching, other bushy hard coral, Fungiidae, massive hard coral, encrusting hard); soft coral; sponge; gorgonian; bushy red algae (Amphiroa crassa); carbonate rock covered with filamentous algae; sand; mixed sand and rubble.

Surface topography was quantified along a $3 \mathrm{~m}$ transect placed to record the maximum vertical relief within each $3 \times 3 \mathrm{~m}$ quadrat. Topography was quantified with a field profile gauge (Fig. 1). The apparatus was pushed onto the substratum along the transect to be quantified, displacing the eleven $1 \mathrm{~m}$ long graduated vertical needles that slid through a central support frame. Needles were placed $10 \mathrm{~cm}$ apart, and could be secured in the reference frame by locking screws. A level determined when the reference frame was horizontal and the height of the needles from the substratum to the top of the frame was recorded. This yielded the height of the substratum from a constant reference point. The profile gauge was deployed endon-end 3 times to comprise the $3 \mathrm{~m}$ topography transect. The first deployment of the gauge in a transect included the highest substratum point on the transect. At this point the reference frame was deployed such that one of the needles was maximally depressed. This standardised the height data to allow comparisons among topography transects. The height of the reference frame was adjusted in subsequent profiles of the $3 \mathrm{~m}$ transect to maintain a constant horizontal reference point.

Data from these 100 quadrats were used in the comparison of measures of surface topography and to examine the interrelationships among reef topography, cover of benthic organisms and fish assemblages.

Comparison of surface topography measures. Six methods of quantifying surface topography were compared to determine which was best at differentiating among types of architecture.

(1) Consecutive substratum height difference. A summation of the squared differences between the heights of consecutive needles gave a measure of topography for a transect. Values were square root transformed to linearise the index. This statistic has not previously been used as a measure of topography.

(2) Angular standard deviation of vectors normal to the line joining 2 consecutive needle heights along a profile transect $\left(\theta_{1}\right.$, Fig. $\left.1 \mathrm{~b}\right)$. This is a 2 -dimensional modification of the variance of vectors normal to a planar surface, termed 'vector dispersion', used by Carleton \& Sammarco (1987) to quantify the surface geometry of small plate corals. In the present study,
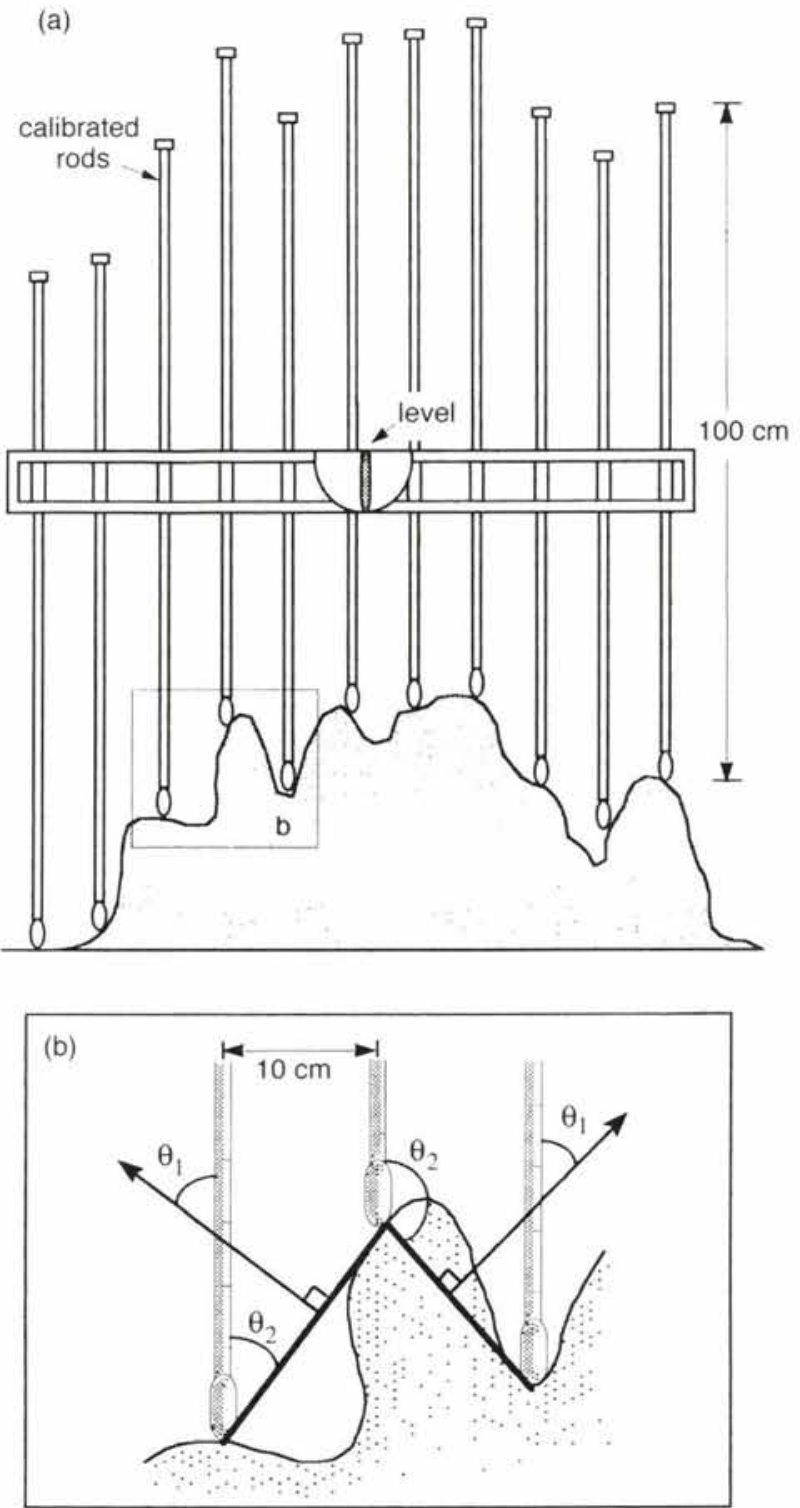

Fig. 1. (a) Profile gauge used to measure surface topography. Inset (b) shows the angular measures used in the calculation of vector $\operatorname{SD}\left(\theta_{1}\right)$ and substratum angle $\operatorname{SD}\left(\theta_{2}\right)$

vector angles to vertical are calculated by simple trigonometry, with angular standard deviations calculated using the formula in Zar (1984). This will subsequently be known as 'vector standard deviation'.

(3) Angular standard deviation of the angles formed by a line joining 2 consecutive needle heights and vertical $\left(\theta_{2}\right.$, Fig. 1b). This will be referred to as 'substratum angle standard deviation'.

(4) Contoured versus linear length. This is the widely used 'chain-and-tape' method of Risk (1972), and is calculated as ratio of a length of chain moulded to the surface to the linear distance between its start and end point. This is a generalisation of many of the tech- 
niques used to quantify 3-dimensional surfaces (e.g. Hobson 1972, Dahl 1973).

(5) Standard deviation of regularly measured substratum heights.

(6) Coefficient of variation of the regularly measured substratum heights.

Comparison of these descriptive statistics was done in 3 ways. Firstly, the ability of the methods to discriminate between substrata possessing varying numbers and heights of corrugation was assessed by simulation. Measurements of profile heights were recorded at regular intervals along a 20 unit distance that had between 1 and 5 regularly spaced corrugations $(2$ units wide) that varied in height from 5 to 25 units (in increments of 5 units, yielding 25 frequency by amplitude combinations). These profile height measurements were then used in the calculation of all topography statistics, with the exception of the contoured to linear length that was calculated as defined.

Secondly, methods were simulated on 9 schematic profiles, spanning a range of shapes that are likely to be encountered in a coral reef survey (Fig. 2). For each profile, height differences were measured between a fixed horizontal reference and 21 regularly spaced points to cover the whole profile. Each profile was sampled 3 times from a randomly located start position and the same horizontal reference line. The 6 descriptive statistics were calculated as for the first comparison.

Thirdly, a field study examined the strength and consistency of the relationships between each of the methods and 4 fish assemblage parameters: total fish abundance, number of species, total benthic pomacentrid abundance, total planktivorous pomacentrid abundance. The last 2 parameters were chosen since it is the small site-attached species that might be expected to be influenced most by local substratum characteristics. A strong correlation between a particular measure of surface topography and these fish assemblage parameters suggest that the topography statistic is quantifying a feature of the surface that is potentially influencing patterns of fish distribution and abundance. All 6 topography statistics were calculated using data from the $3 \mathrm{~m}$ profile gauge transects. For the contoured-tolinear distance ratio, contoured length was determined trigonometrically as the summation of the linear distance between consecutive needle heights.

Inter-relationship of reef topography, benthic and fish assemblages. The inter-relationship of reef topography, substratum characteristics and fish fauna within $3 \times 3 \mathrm{~m}$ quadrats was examined to ascertain the

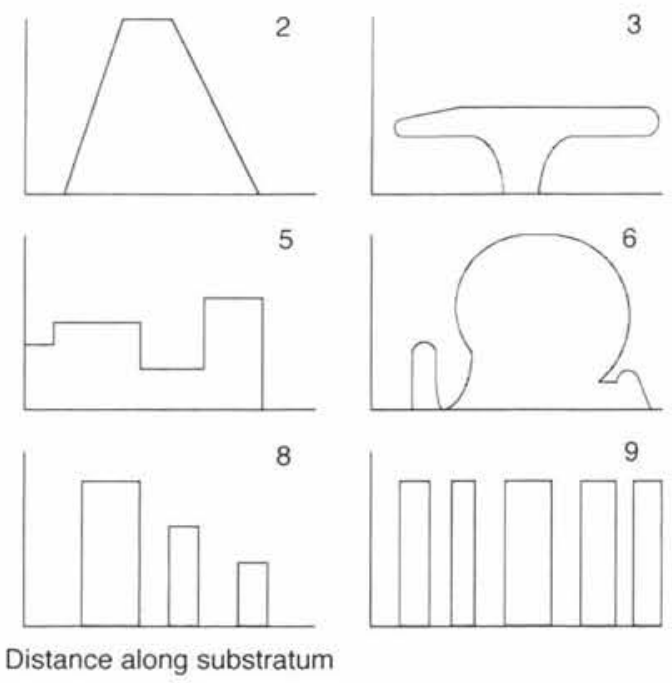

3

9

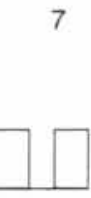

Distance along substratum surface rugosity

strength of the relationship between topography and the fish assemblage at the scale measured. The consecutive substratum height difference statistic, calculated from data collected with the profile gauge, was used as the measure of surface topography because it proved to be one of the best methods of quantifying surface topography (see 'Results' section). Canonical correlation analysis (CCA; Tabachnick \& Fidell 1989) was used to examine and display the often complex relationships. This technique is analogous to running a multiple regression on the benthic and fish data separately, but constraining the linear models generated so that they maximally correlate with one another. CCA identifies a number of linear trends in the data sets that are orthogonal to one another and sequentially explain less of the overall correlation between the physical and biological data sets (canonical variates).

\section{RESULTS}

\section{Comparison of surface topography measures}

Simulations showed that all but one of the methods were able to differentiate between surfaces differing in number and height of corrugation. The exception was the coefficient of variation $(\mathrm{CV})$ of the substratum heights which, because it was standardised by the mean substratum height, could not differentiate among surfaces that differed in corrugation height (for a given number of corrugations). All other techniques showed trends that were very similar to each other. For example, Fig. 3 shows the results for the consecutive height difference method. Surfaces of the same height but which differed in the number of corrugations were 
well discriminated, as were surfaces of the same number of corrugations with differing corrugation height. However, in all these methods there was substantial overlap in index values between surfaces with 1 large ridge and those with many small corrugations. Thus, all methods (except CV) were able to grossly differentiate among topographies of varying complexity. The influence of the spatial arrangement of the corrugations (i.e. whether clumped, random or regular) on the discriminatory ability of the methods awaits further study.

An examination of the ability of the topography measures to differentiate among 9 schematic profiles showed that 3 methods had similar discriminatory ability: the consecutive substratum height difference, substratum angle standard deviation and vector standard deviation (Fig. 4).

The consecutive height difference measure has a value of 0 on flat surfaces, while large values correspond to increasing surface topography. The asymptotic limit of the index will be governed by the maximum difference between consecutive substratum heights and the number of needles used in the topography transect (which was kept constant in this study). The latter should be standardised within and between surveys for comparative purposes.

The 2 angular standard deviations (methods $2 \& 3$ ), ranged from 0 (constant orientation) to 1 (large and diverse substratum angles). This had the advantage of conceptual simplicity, although the actual value of the index will again be determined by the density of needles used to quantify the profile. The substratum-angle standard deviation ranked the angularly simplistic pyramid equally to the more complex undulating slope (profile 4).

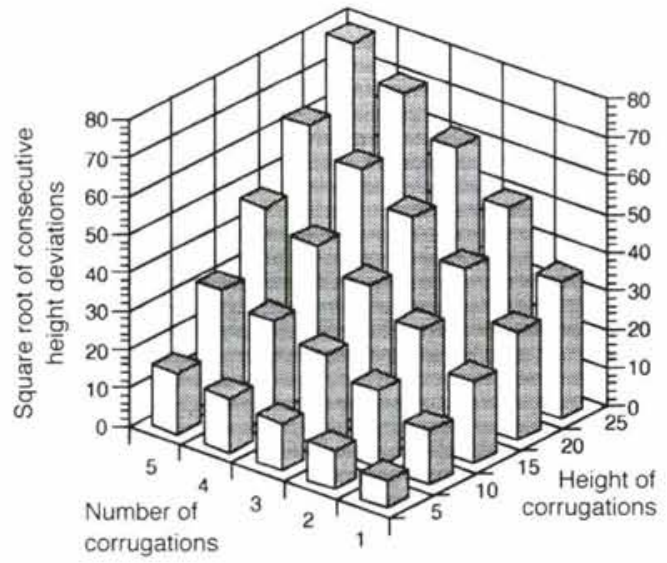

Fig. 3. Comparison of the ability of one measure of surface topography (square root of the difference of consecutive needle heights) to discriminate between simulated surfaces that vary in the number and heights of corrugations
The ratio of linear versus contoured distance ('chain-and-tape' method) grossly quantified topographic complexity, with a flat surface scoring a value of 1 and the most complex corrugated surface having a value closer to 0 . This method could not differentiate among substrata with low corrugations, inclined corrugations, a tabulate outcrop or a globular bommie. Nor could it differentiate between a pyramid and a series of variably sized undulations (Fig. 4).

The standard deviation of the substratum heights, by the nature of its calculation, best recorded the variability in heights of the 9 profiles. However, it did not take into account how these heights were distributed relative to one another. Consequently, it could not differentiate between a tabulate outcrop and a series of shallow undulations (Fig. 4).

The CV of substratum heights, due to its standardisation, loses information on the height of substrata that is valuable in the differentiation among profiles. It also suffers from the same limitations as the standard deviation of heights.

When the relationship between the 6 measures of topography and 4 fish assemblage parameters (sampled from 100 quadrats of $3 \times 3 \mathrm{~m}$ ) was examined all measures yielded low correlations $(r<0.45$, Table 1$)$. The consecutive height deviations method performed consistently well, scoring the highest average correlation. This was closely followed by the vector standard deviations. Substratum height standard deviation and $\mathrm{CV}$ of substratum height attained the lowest correlations with the community parameters, obtaining nonsignificant correlations with the total abundance of benthic pomacentrids.

Correlations between the 50 most common fish species and measures of substratum relief were generally poor. The consecutive height difference method had by far the highest number of significant correlations with fish species (although $5 \%$ of these could be expected by chance alone, at the $\mathrm{p}<0.05$ significance level). This method also had the 2 highest univariate correlations with species abundance, attaining correlation coefficients of 0.49 with juveniles of the planktivore Neopomacentrus azysron and 0.42 with planktivores of genus Chromis.

Pearson correlations among the 6 topography indices, measured in the 100 quadrats, were surprisingly low given all were generated from the same data as measures of rugosity ( $\mathrm{r}$ of -0.167 to -0.895 , Table 2 ). The large amount of variability unexplained by these relationships (20 to $97 \%$ ) stresses that each index is quantifying slightly different aspects of surface topography. Highest correlations were obtained among combinations of methods $1,2 \& 4$ (i.e. consecutive height difference, vector standard deviation and the straight versus contoured distance). 

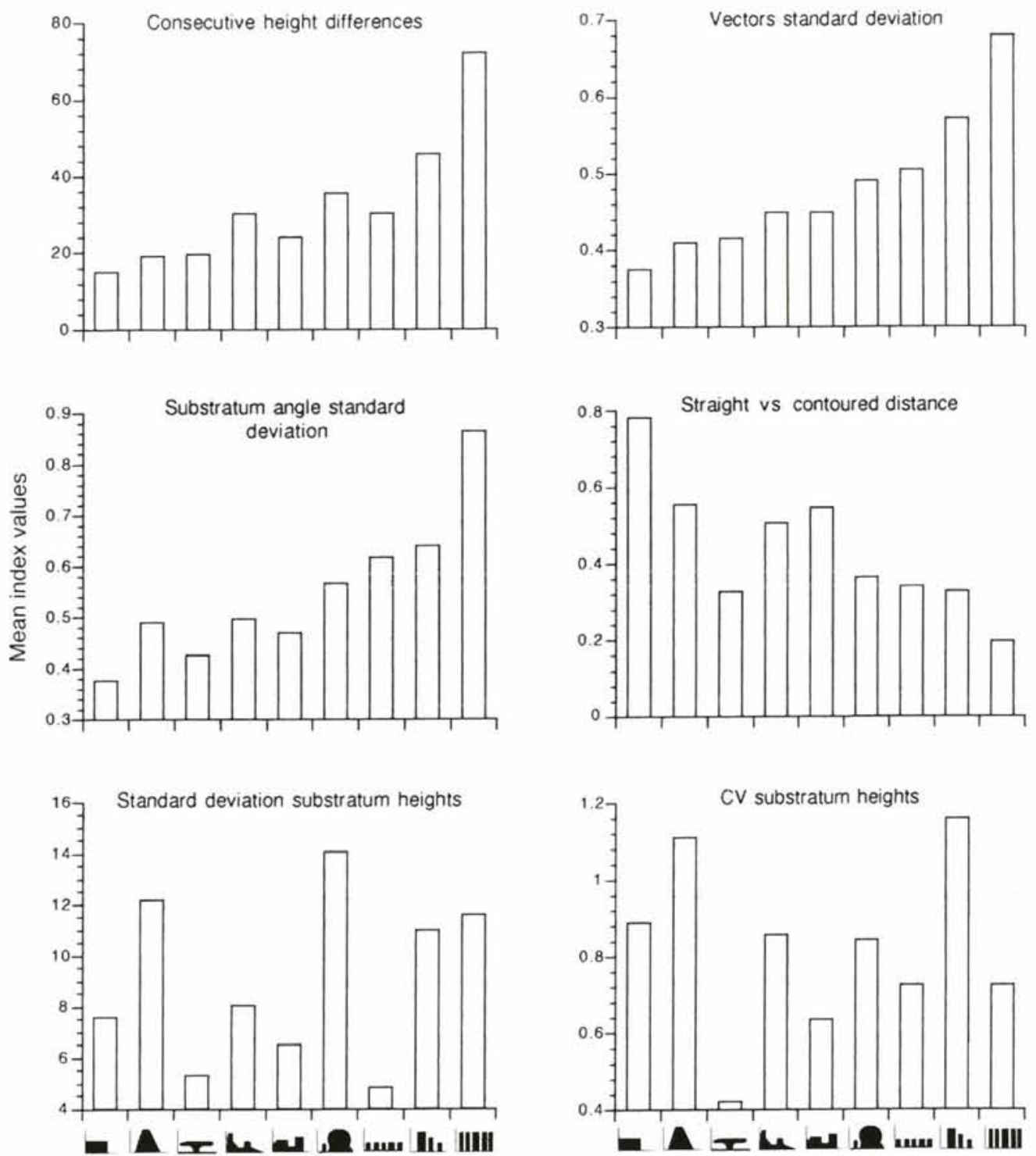

Fig. 4. Comparison of 6 methods of quantifying surface topography by simulation over 9 profiles. Mean values ( $\mathrm{n}=3$ ) for each topography measure are given for each of the profiles in Fig. 2

Profiles

Table 1. Relationship between 6 measures of substratum topography and 4 fish assemblage parameters measured in 100 quadrats of $3 \times 3 \mathrm{~m}$. Pearson's correlation coefficients and significance levels are given (ns: non-significant at $p=0.05 ; \cdot p<0.05$; $\cdots p<0.005 ; \cdots p<0.0001)$. The number of significant correlations between the 50 most common fish species in the quadrats and the 6 measures of topography are also given $(p<0.05)$

\begin{tabular}{|c|c|c|c|c|c|c|}
\hline $\begin{array}{l}\text { Fish assemblage } \\
\text { parameter }\end{array}$ & $\begin{array}{l}\text { Oonsecutive height } \\
\text { differences }\end{array}$ & $\mathrm{SD}$ vector & $\begin{array}{l}\text { SD substratum } \\
\text { angle }\end{array}$ & $\begin{array}{l}\text { Straight vs } \\
\text { contoured }\end{array}$ & $\begin{array}{l}\text { SD substratum } \\
\text { height }\end{array}$ & CV height \\
\hline Total abundance & $0.409 \cdots$ & $0.352 \cdots$ & $0.211^{\circ}$ & $-0.317^{\cdots}$ & $0.307^{\cdots}$ & $0.279^{*}$ \\
\hline No. of species & $0.410 \cdots$ & $0.441 \cdots$ & $0.283^{\cdots}$ & $-0.444 \cdots$ & $0.152 \mathrm{~ns}$ & $0.263 *$ \\
\hline $\begin{array}{l}\text { Total abundance: } \\
\text { benthic pomacentrids }\end{array}$ & $0.324 \cdots$ & $0.328 \cdots$ & $0.261 \cdots$ & $-0.310^{*}$ & $0.171 \mathrm{~ns}$ & $0.075 \mathrm{~ns}$ \\
\hline $\begin{array}{l}\text { Total abundance: } \\
\text { planktivorous pomacentrids }\end{array}$ & $0.412 \cdots$ & $0.287^{*}$ & $0.203^{\circ}$ & $-0.311 \cdots$ & $0.377 \cdots$ & $0.300 *$ \\
\hline $\begin{array}{c}\text { No. of significant fish species } \\
\text { by topography correlations }\end{array}$ & 18 & 12 & 4 & 12 & 11 & 11 \\
\hline
\end{tabular}


Table 2. Pearson correlations among 6 measures of surface topography measured in 100 quadrats of $3 \times 3 \mathrm{~m}$. All are significant at $\mathrm{p}<0.0001$ except where indicated by ns

\begin{tabular}{|c|c|c|c|c|c|}
\hline Topography measure & SD vector & $\begin{array}{l}\text { SD substratum } \\
\text { angle }\end{array}$ & $\begin{array}{l}\text { Straight vs } \\
\text { contoured }\end{array}$ & $\begin{array}{c}\text { SD substratum } \\
\text { height }\end{array}$ & $\mathrm{CV}$ height \\
\hline Consecutive height differences & 0.761 & 0.521 & -0.8780 & 0.4261 & 0.4731 \\
\hline SD vector & & 0.676 & -0.8946 & 0.3583 & 0.4707 \\
\hline SD substratum angle & & & -0.5494 & 0.3514 & 0.3450 \\
\hline Straight vs contoured & & & & $-0.1665 \mathrm{~ns}$ & -0.3341 \\
\hline SD substratum height & & & & & 0.8017 \\
\hline
\end{tabular}

\section{Interrelationship of reef topography, benthic and fish assemblages}

To examine the importance of surface topography in influencing fish distributions the relationship of the fish community with benthic cover and surface topog-

(a) Pomacentrids

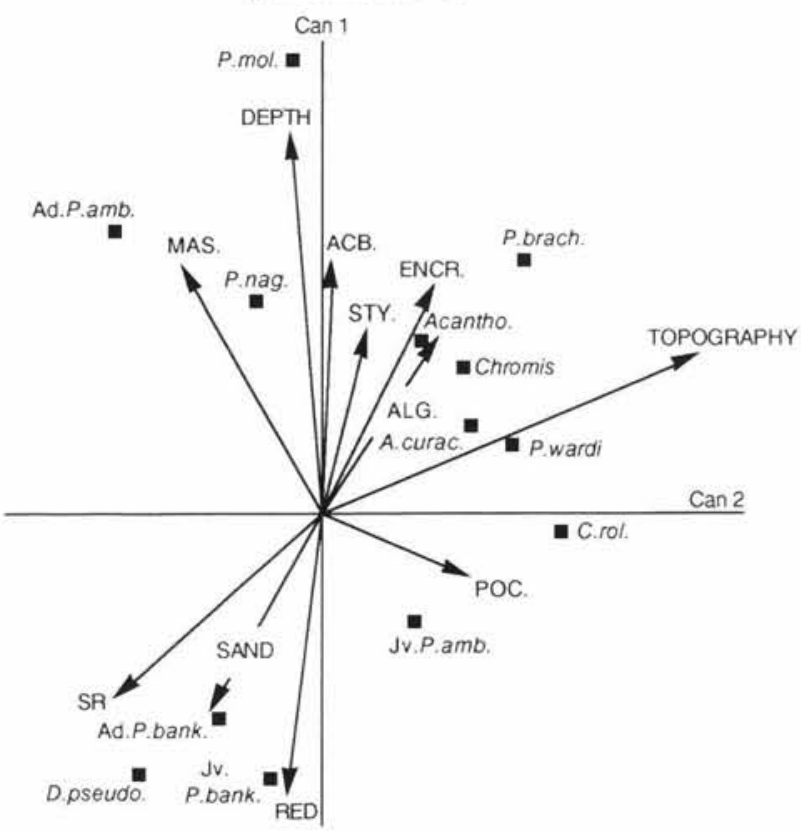

raphy was examined. The consecutive height difference method was used as the measure of surface topography as it had performed well in the previous analyses. Data were divided up into 2 data sets: the small territorial pomacentrids, and other more widely ranging fish species. Fig. 5a presents an ordination

(b) Non-pomacentrids

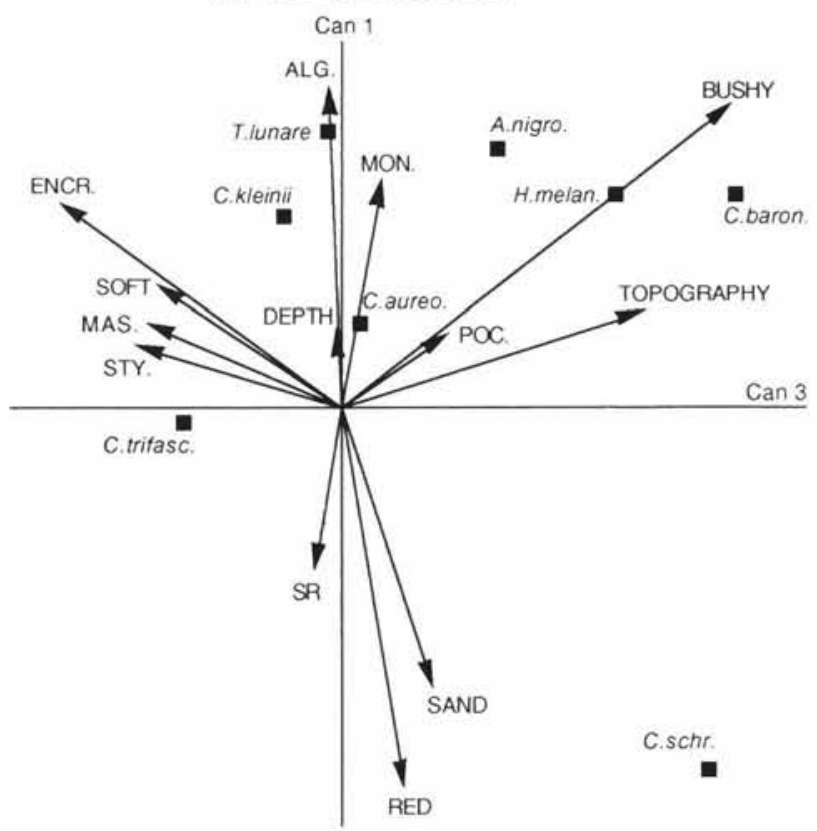

Fig. 5. Canonical correlation analysis showing the relationships of the fish community with cover of benthic invertebrates and surface topography (quantified as the sum of consecutive substratum height differences measured every $10 \mathrm{~cm}$ along a $3 \mathrm{~m}$ transect). Pomacentrids (a) and non-pomacentrid reef fish (b) were analysed separately.

Fish species:

Acantho $=$ Acanthochromis polyacanthus

A.nigro $=$ Acanthurus nigrofuscus

A. curac $=$ Amblyglyphidodon curacao

C.aureo $=$ Chaetodon aureofasciatus

C. baron $=$ C. baronessa

C. kleinii $=C$. kleinii

C.trifasc $=$ C. trifasciatus

C.rol $=$ Chrysiptera rollandi

Chromis $=$ Chromis spp.

C.schr $=$ Coris schroederi
D.pseudo $=$ Dischistodus pseudochrysopoecilus

H.melan $=$ Halichoeres melanurus

P.amb $=$ Pomacentrus amboinensis

P. bank $=P$. bankanensis

[latter 2 species subdivided into adults (Ad.) and juveniles (Jv.)]

P. brach $=$ P. brachialis

P.mol $=$ P. moluccensis

P.nag $=$ P. nagasakiensis

P. wardi $=P$. wardi

T.lunare $=$ Thalassoma lunare
Benthic categories:

$\mathrm{ACB}=$ branching Acropora

$\mathrm{ALG}=$ filamentous algal covered carbonate rock

BUSHY $=$ all bushy hard corals

ENCR = encrusting hard coral

MAS = massive hard coral

MON $=$ Montipora

POC $=$ Pocillopora

RED $=$ red algae (Amphiroa crassa)

SOFT $=$ soft coral

$\mathrm{SR}=$ sand and rubble

STY $=$ Stylophora 
diagram for the pomacentrid reef fish. Axes 1 and 2 cumulatively account for $51 \%$ of the total variance, with species-environment correlations of 0.79 (Axis 1) and 0.72 (Axis 2). The main trends in the environmental variables that were important in resolving the distribution patterns of fishes were depth (Axis 1) and, secondarily, topography (Axis 2). Trends in the fish assemblage can be readily interpreted with respect to these benthic gradients. For example, the juvenile damselfish Pomacentrus amboinensis recruited into shallow areas dominated by the bushy hard coral Pocillopora sp., while the adults occurred in deeper water associated with massive corals and sand and rubble. Pomacentrus brachialis, P. wardi, Acanthochromis and Chromis species were associated with areas of moderate to high surface topography, while Pomacentrus bankanensis and Dischistodus pseudochrysopoecilus were associated with areas of low topography.

Fig. 5b represents an ordination diagram for the more widely ranging non-pomacentrid reef fish, with Axes 1 and 3 accounting for $57 \%$ of the total variability. For this group of fish, surface topography (as measured) was a less important environmental gradient than was found for the pomacentrids. It was a moderate contributor to the third major environmental gradient identified in the analysis.

\section{DISCUSSION}

Few studies have examined the extent to which substratum topography explains the small-scale spatial distribution patterns of temperate and tropical reef fishes. Of the studies that have, most have used the 'chain-and-tape' (i.e. contoured-to-linear distance) method developed by Talbot \& Goldman (1972) and Risk (1972) (e.g. Luckhurst \& Luckhurst 1978, Leum \& Choat 1980, references in Jones 1988b Table 2, Connell \& Jones 1991, Grigg 1994), although a number of other methods have been used. Luckhurst \& Luckhurst (1978) calculated the mean value of 49 regularly sampled substratum heights for each of 16 quadrats $(3 \times$ $3 \mathrm{~m}$ ) as a measure of vertical relief. Choat \& Bellwood (1985) used the raw values of 75 substratum heights from each of 2 sites in a ANOVA comparison of the variability of reef structure among sites. None of the studies examined which specific features of surface complexity the techniques were quantifying. This study found that 6 measures of surface topography, 3 of which had been used by previous studies, differed in their ability to differentiate among reef profiles of varying topography.

All but one measure of topography used in this study (CV of substratum heights) could grossly, although sys- tematically, differentiate among profiles that varied in the frequency and magnitude of corrugation. The typically used 'chain-and-tape' method performed well but did not yield the highest correlations with fish community parameters or fish species abundance when trialed on field data. The new method introduced in this paper, using a field profile gauge and obtaining the summed difference between consecutive regularly sampled substratum heights, performed marginally better than all other techniques. Furthermore, deployment of the profile gauge was rapid (a $3 \mathrm{~m}$ transect took $\sim 5 \mathrm{~min}$ ) and data collected allowed the calculation of more than 1 measure of surface complexity. Mean values (arithmetic or angular) were not trialed in the comparison of topography measures since these contain no information on the variability. Such information is important for the differentiation of complex profiles. Variance estimates have the advantage of containing information on corrugation frequency and amplitude, the 2 important components for differentiating between surfaces of varying absolute surface areas (Hobson 1972, Dahl 1973).

Indices that used information on the order of the substratum heights in some form gave better discrimination than those that did not. Standard deviation of substratum heights and its associated $\mathrm{CV}$ do not incorporate information on the spatial arrangement of the substratum heights. The calculation of these indices resulted in the loss of information on angularity or bumpiness of the substratum that is a function of the differences in height between adjacent regularly sampled points. For this reason these parameters are not recommended as rugosity measures.

Few comparisons of ways of measuring surface topography have been undertaken. Underwood \& Chapman (1989) compared the relative ability of the contoured versus planar surface area method (analogous to the 'chain-and-tape' method), angular and standard variance of substratum heights to differentiate among eight 3-dimensional substratum complexities. Surfaces were generated by altering the spatial arrangement and frequency of depressions, whilst maintaining the depressions at a constant depth. Similarly to the present study, they found that the ratio of actual to flat surface areas and angular variance were better descriptions of complexity than a simple measure of variance (note: Fig 1.2 in Underwood \& Chapman 1989 is incorrect and should look like their Fig 1.3; Underwood pers. comm.). Carleton \& Sammarco (1987) compared the relationships of 6 measures of surface relief of 12 pieces of plate coral to the density, species diversity and dispersion of coral spat that recruited to those plates. Three were derivations of a standard deviation of regularly measured vertical heights, while the others were average surface angle, 
vector variance (analogous to vector standard deviation in this study) and vector strength. Methods performed in a similar way to the 2-dimensional analogues in the present study, with standard deviations of height measures performing worst and vector variance the best, yielding the highest correlation with spat density.

In the present study, a different relationship between the fish assemblage and surface complexity may have been obtained had the average topography of each quadrat been obtained rather than the maximum. If an average value was to be used then less information would be lost if a grid of substratum heights was sampled and deviations in height were calculated as deviations (and angles) of the planar triangular surfaces connecting 3 adjacent measurement points. Hobson (1972) and Carleton \& Sammarco (1987) give the calculations for angular representations of planar surfaces. The gain in information obtained will cost time (and money) and result in a reduction in the total number of sampling units able to be allocated to a study. This may make 3-dimensional field measures of surface complexity prohibitive in correlative studies due to the large number of replicate sampling units required. It is also interesting to note that the 2 dimensional measure of maximum surface topography used in the present analysis was only second to depth in explaining the distribution patterns of pomacentrid reef fish at the scale sampled.

The results of all topography measures are dependent on the scale of measurement. When using a profile mapping method, the distance between vertical measurements and their number, govern the scale at which heterogeneity will be quantified. Likewise, for the 'chain-and-tape' method it is the length of the chain and size of the linkages that will govern the index value. It is crucial to measure substratum variables at the scale that is important to the organism of interest, rather than logistically easiest to sample. A poor correlation between the density of an organism and topography does not necessarily mean that complexity is unimportant in determining its distribution, but rather may be indicative of measurements taken at the wrong scale. Many of the poor correlations between substratum variables and fish assemblages found to date may stem from this difficulty.

The appropriateness of a scale of sampling is likely to change with the ontogeny of the study organisms; the requirements of food and shelter for a recruit are likely to differ from those of an adult. Connell \& Jones (1991) found blanket settlement of the tripterygiid Forsterygion varium to a temperate reef was followed by high mortality in areas of 'low' complexity (measured by chain-and-tape). One hypothesis they suggested was that their measure of rugosity was too coarse to adequately measure shelter available to the juveniles; recruits found adequate shelter but subsequently outgrew suitable shelter sites in 'low' complexity areas. The techniques discussed in the present study can be modified (i.e. scaled up or down) and applied at any scale (tens of metres to centimetres) to obtain a multiscale appreciation of how all reef associated life stages of a fish species relate to their habitats.

Analysis of the field data presented emphasises that the assessments of structural relief provide a description of the habitat complexity of the reef surface that is complementary to data on benthic composition rather than an alternative. None of the techniques can uniquely identify all possible combinations of corrugation frequency and amplitude. Moreover, the techniques are limited in their ability to quantify specific surface features of particular interest, such as the size and density of holes (shelter sites) or the presence of overhangs. A combination of habitat complexity descriptors will give the most informative representation of the relationships between habitat structure and fish assemblages (e.g. Wilkins \& Myers 1992). Categorical analyses, that will take both quantitative and qualitative data (presence/absence of structures, or indices of occurrence), are widely available on most multivariate statistical packages (e.g. correspondence analysis).

Measurements of surface complexity using the methods discussed in this study not only enabled an objective discrimination among the topographies of study units but also provided a quantitative continuous measure of relief. To date, these summaries of overall benthic structural complexity have been underutilised. Estimates of surface topography may be useful as covariates to factor out some of the variability in spatial abundance patterns of organisms thereby yielding more sensitive tests for environmental monitoring or impact studies. When surface topography is measured over a range of spatial scales, as one of a number of measures of habitat complexity, it may elucidate the scales at which associations between fish assemblages and their habitat occur. This will determine the scale at which experiments are conducted that examine the nature of these associations.

Acknowledgements. I am indebted to L. Axe, B. Kerrigan and K. Tricklebank for assisting with field work. G. Jones, B. Kerrigan, C. Syms, M. Caley and 3 anonymous reviewers provided valuable criticisms of the manuscript. This research was funded by the Australian Museum and the Australian Research Council. Logistic support was provided by the Department of Marine Biology, James Cook University This paper is a contribution from the Lizard Island Research Station, a facility of the Australian Museum. 


\section{LITERATURE CITED}

Bell, J. D., Galzin, R. (1984). Influence of live coral on coralreef fish communities. Mar. Ecol. Prog. Ser. 15: 265-274

Bouchon-Navaro, Y., Bouchon, C. (1989). Correlations between chaetodontid fishes and coral communities of the Gulf of Aqaba (Red Sea). Environ. Biol. Fish. 25: 47-60

Carleton, J. H., Sammarco, P. W. (1987). Effects of substratum irregularity on success of coral settlement: quantification by comparative geomorphological techniques. Bull. mar. Sci. 40: 85-98

Carpenter, K. E., Miclat, R. I., Albaladejo, V. D., Corpuz, V. T. (1981). The influence of substratum structure on the local abundance and diversity of Philippine reef fishes. Proc. 4th int. coral Reef Symp. 2: 495-502

Choat, J. H., Bellwood, D. R. (1985). Interactions amongst herbivorous fishes on a coral reef: influence of spatial variation. Mar. Biol. 89: 221-234

Connell, S. D., Jones, G. P. (1991). The influence of habitat complexity on post-recruitment processes in a temperate reef fish population. J. exp. mar. Biol. Ecol. 151: 271-294

Crisp, D. J., Barnes, H. (1954). The orientation and distribution of barnacles at settlement with particular reference to surface contour. J. Anim. Ecol. 23: 142-162

Dahl, A. L. (1973). Surface area in ecological analysis: quantification of benthic coral-reef algae. Mar. Biol. 23: 239-249

Eckert, G. J. (1985). Settlement of coral reef fishes to different natural substrata and at different depths. Proc. 5th int. coral Reefs Congr. 5: 385-390

Green, A. L. (1994). Damselfish territories: focal sites for studies of the early life history of labroid fishes. Proc. 7 th int. coral Reef Symp. (in press)

Grigg, R. W. (1994). Effects of sewage discharge, fishing pressure and habitat complexity on coral ecosystems and reef fishes in Hawaii. Mar. Ecol. Prog. Ser. 103: 25-34

Hacker, S. D., Steneck, R. S. (1990). Habitat architecture and the abundance and body-size-dependent habitat selection of a phytal amphipod. Ecology 71: 2269-2285

Hixon, M. A., Beets, J. P. (1993). Predation, prey refuges, and the structure of coral-reef fish assemblages. Ecol. Monogr. 63: 77-101

Hobson, R. D. (1972). Surface roughness in topography: quantitative approach. In: Chorley, R. J. (ed.) Spatial analysis in geomorphology. Methuen and Co., Ltd, London. p. $221-245$

Jones, G. P. (1988a). Experimental evaluation of the effects of habitat structure and competitive interactions on the juveniles of two coral reef fishes. J. exp. mar. Biol. Ecol. 123: $115-126$

Jones, G. P. (1988b). Ecology of rocky reef fish of north-eastern New Zealand: a review. N.Z. J. mar. Freshwat. Res. 22: 445-462

Leum, L. L., Choat, J. H. (1980). Density and distribution patterns of the temperate marine fish Cheilodactylus spectabilis (Cheilodactylidae) in a reef environment. Mar. Biol. 57: $327-337$

Levin, P. S. (1991). Effects of microhabitat on recruitment variation in a Gulf of Maine reef fish. Mar. Ecol. Prog. Ser. 75: $183-189$

This article was presented by D. M. Alongi (Senior Editorial Advisor), Townsville, Australia
Luckhurst, B. E., Luckhurst, K. (1978). Analysis of the influence of substrate variables on coral reef fish communities. Mar. Biol. 49: 317-323

Marliave, J. B. (1977), Substratum preferences of settling larvae of marine fishes reared in the laboratory. J. exp. mar. Biol. Ecol. 27: 47-60

McCoy, E. D., Bell, S. S. (1991). Habitat structure: the evolution and diversification of a complex topic. In: Bell, S. S, McCoy, E. D., Mushinsky, H. R. (eds.) Habitat structure the physical arrangement of objects in space. Chapman \& Hall, London, p. 3-27

McManus, J. W., Miclat, R. I., Palaganas, V. P. (1981). Coral and fish community structure of Sombrero Island, Batangas, Philippines. Proc. 4th int. coral Reef Symp. 2: $271-280$

Raffaelli, D. G., Hughes, R. N. (1978). The effects of crevice size and availability on populations of Littorina rudis and Littorina neritoides, J. Anim. Ecol. 47: 71-84

Reese, E. S. (1989). Orientation behavior of butterflyfishes (family Chaetodontidae) on coral reefs: spatial learning of route specific landmarks and cognitive maps. Environ. Biol. Fish. 25: 79-86

Risk, M. J. (1972). Fish diversity on a coral reef in the Virgin Islands. Atoll Res. Bull. 193: 1-6

Roberts, C. M. (1987). Experimental analysis of resource sharing between herbivorous damselfish and blennies on the Great Barrier Reef. J. exp. mar. Biol. Ecol. 111: $61-75$

Roberts, C. M., Ormond, R. F. G. (1987). Habitat complexity and coral reef fish diversity and abundance on Red Sea fringing reefs. Mar. Ecol. Prog. Ser. 41: 1-8

Russ, G. R. (1980). Effects of predation by fishes, competition and structural complexity of the substratum on the establishment of a marine epifaunal community. J. exp. mar. Biol. Ecol. 42: 55-69

Sale, P. F. (1978) Coexistence of coral reef fishes - a lottery for living space. Environ. Biol. Fish. 3: 85-102

Sale, P. F., Douglas, W. A., Doherty, P. J. (1984). Choice of microhabitats by coral reef fishes at settlement. Coral Reefs 3: 91-99

Sebens, K. P. (1991). Habitat structure and community dynamics in marine benthic systems. In: Bell, S. S., McCoy, E. D., Mushinsky, H. R. (eds.) Habitat structure - the physical arrangement of objects in space. Chapman \& Hall, London, p. 211-234

Tabachnick, B. G., Fidell, L. S. (1989). Using multivariate statistics. Harper \& Row, New York

Talbot, F. H., Goldman, B. (1972). A preliminary report on the diversity and feeding relationships of the reef fishes of One Tree Island, Great Barrier Reef system. Proc. 1st int. coral Reef Symp. 1: 425-440

Underwood, A. J., Chapman, M. G. (1989). Experimental analyses of the influences of topography of the substratum on movements and density of an intertidal snail, Littorina unifasciata. J. exp. mar. Biol. Ecol. 134: 175-196

Wilkins, H. K. A., Myers, A. A. (1992). Microhabitat utilisation by an assemblage of temperate Gobiidae (Pisces: Teleostei). Mar. Ecol. Prog. Ser. 90: 103-112

Zar, J. H. (1984) Biostatistical analysis, 2nd edn. Prentice-Hall International, Englewood Cliffs, p. 718

Manuscript first received: March 7, 1994

Revised version accepted: May 25, 1994 